\title{
An Epidemiological Study to Assess Prevalence and Risk factors Associated with Diabetes Among Adolescents in Urban Areas of Udaipur \\ Mitin Parmar ${ }^{1}$, Gourav Kumar Goyal' ${ }^{2}$, Kalika Gupta ${ }^{3}$, Milan Chaudhary ${ }^{4}$ \\ ${ }^{1}$ Associate Professor, ${ }^{3}$ Assistant Professor, ${ }^{4}$ Senior resident, Department of Community Medicine, ${ }^{2}$ Assistant Professor, Department of Paediatrics, Ananta Institute of Medical Sciences and Research Centre, Rajsamand, Rajasthan Correspondence : Dr. Kalika Gupa, Email : kalikagupta007@gmail.com
}

\begin{abstract}
:
Introduction: Adolescents constitute $20 \%$ of world's total population. Adolescents have become quite vulnerable to various non-communicable diseases (NCDs) like hypertension and diabetes mellitus, especially due to the tremendous changes in their lifestyle over the last few decades. The age of onset of Type 2 diabetes in India has been shifting towards ever younger people. Among Indians in their late teens [15-19 years], Type 2 diabetes already manifests itself more often than Type 1 diabetes does. Objective: To study prevalence and risk factors for Type 2 diabetes and pre diabetes among male and female adolescents in Udaipur city. Method: It was a Community based cross sectional study conducted in three urban areas of Udaipur for 6 months. A total of 1005 adolescents were included in the study. A pretested and predesigned questionnaire was used. Results: Prevalence of diabetes was $2.9 \%$ in males and $4.4 \%$ in females adolescents. Prevalence of smoking, alcoholism, non-vegetarian diet and hypertension was higher among males. Conclusion: Diabetes type 2 is a growing problem among adolescents. We need active involvement of health care workers for educating adolescents about risk factors for diabetes.
\end{abstract}

Key words: Adolescents, Diabetes, Pre-Diabetes.

\section{Introduction:}

According to the WHO, adolescence is defined as the period between 10 to 19 years, the second decade of life. This is a period of rapid growth and development for adolescents' bodies, minds and social relationships. ${ }^{[1]}$ Adolescence is a process whereby an individual makes the gradual transition from childhood to adulthood and is a critical period of development, second only to the early childhood years. Adolescents constitute $20 \%$ of world's total population. $^{[2]}$

According to 2011 Census of India, there are 253.2 million adolescents constituting $20.9 \%$ of the total population. ${ }^{[3]}$ This number is ever increasing making it the largest generation to undergo transition from children to adults in the near future, in turn making India the youngest country of the world.

Adolescents have become quite vulnerable to various non-communicable diseases (NCDs) like hypertension and diabetes mellitus, especially due to the tremendous changes in their lifestyle over the last few decades. Over half of NCD related deaths are associated with behaviours that begin or are reinforced during adolescence, including tobacco and alcohol use, poor eating habits, and lack of exercise, compounded by the presence of obesity. ${ }^{[4]}$

\begin{tabular}{|c|c|c|}
\hline Quick R & Acce & \\
\hline \multirow{2}{*}{ aring } & $\begin{array}{l}\text { Web } \\
w w V\end{array}$ & \multirow{2}{*}{$\begin{array}{l}\text { Parmar M, Goyal G K, Gupta K, Chaudhary M. An } \\
\text { Epidemiological Study to Assess Prevalence and Risk } \\
\text { factors Associated with Diabetes Among Adolescents } \\
\text { in Urban Areas of Udaipur. Healthline. 2021; } 12 \\
\text { (1):22-28 }\end{array}$} \\
\hline & $\begin{array}{l}\text { DOI : } \\
\text { 10.51957/Healthline_170_2020 }\end{array}$ & \\
\hline
\end{tabular}


Diabetes Mellitus (DM) is a chronic disorder characterized by raised blood sugar levels that occur when the pancreas does not produce enough insulin or when the body cannot effectively use the insulin it produces. ${ }^{[5]}$ The International Diabetes Federation has estimated that about 382 million people all over the world suffer from diabetes. If these trends continue, by 2035 , about 592 million people, or every tenth person, will have diabetes. ${ }^{[6]}$ In India, the overall diabetes prevalence is $8 \%$. Prevalence is only $0.7 \%$ for non-obese, physically active, rural Indians. It reaches $11 \%$ for obese, sedentary, urban Indians. ${ }^{[7]}$ There are about 1 million juvenile diabetics in India, and every year 12000 diabetic children [2-14 years] die of the disease. ${ }^{[8]}$

Global and national estimates for the prevalence of diabetes in the adolescent age group are unavailable till date. In the United States, May et al found out that the combined prevalence of prediabetes \& diabetes in American adolescents was $23 \%$ in 2007-2008. ${ }^{[9]}$ The largest study in India was conducted by Singh et al among 10,843 adolescents in Chandigarh during the year 2007, and they detected a prevalence of diabetes of $4.2 \%{ }^{\left[{ }^{[0]}\right.}$

Although Type 1 diabetes is the most common form in children, Type 2 diabetes poses a major health problem globally, especially in the developing world. The age of onset of Type 2 diabetes in India has been shifting towards ever younger people. Among Indians in their late teens [15-19 years], Type 2 diabetes already manifests itself more often than Type 1 diabetes does. ${ }^{[1]}$ Type 2 diabetes in children and adolescents is probably under-diagnosed because it can exist without symptoms. The clinical manifestations of T2DM are preceded by an asymptomatic prodromal period called 'prediabetes'.

Against the above background, the present study was carried out with the objective to study the prevalence of diabetes and associated risk factors among individuals in the age group 10-19 years in urban areas of Udaipur, Rajasthan.

\section{Method:}

Study Design : Community based cross sectional study.

Study Area : The study was conducted in three urban areas of Udaipur - Bhuwana [population 17660], Fatehpura [2 lakhs population] and Siphon [10000 population]. The three areas were selected as they are catered by the Department of Community Medicine of the medical college.

Study Period : Study was conducted for a period of 6 months from July 2019 to December 2019.

Study Subjects : Males and females of 10-19 years residing in these areas

Sample Size : At 95\% confidence level and taking the prevalence of diabetes and prediabetes to be $9.5 \%$ with a relative error of $20 \%$, the sample size came out to be 934 using the formula

$\mathbf{n}=\mathbf{Z}_{\alpha}^{2} \mathbf{p} \mathbf{q} / \mathbf{L}^{2}$,

Where $\mathrm{n}=$ sample size

$\mathrm{Z} \alpha=1.96$ value of the standard normal variate corresponding to level of significance alpha $5 \%$

$\mathrm{p}=$ prevalence of diabetes $^{[12]}, 9.5 \%$

$q=100-p, 90.5 \%$

$\mathrm{L}=$ precision, $20 \%$

Accounting for a non-response rate of $20 \%$, a total of 1027 subjects were to be included. Out of these, 22 did not give consent to be part of the study, hence 1005 adolescents were included in the study. By simple random sampling, subjects were selected from the three areas. Proportionate probability sampling was followed.

\section{Inclusion Criteria :}

1. All males and females of 10-19 years after getting consent from them and informed written consent from their parents if they are $<18$ years, or after getting consent from them if they are 18 years or older.

2. The person should be a resident of the area mentioned above for a minimum of 6 months. 
Study Instruments : A predesigned, pretested, semistructured questionnaire containing items on (a) identification data i.e. age, gender, religion, educational status, area of residence, socioeconomic status of the person, (b) risk factor for diabetes i.e. obesity, sedentary lifestyle, smoking, alcohol, family history, dietary habits, history of consanguinity, etc. The questionnaire was pilot tested among 20 adolescents in the village of Delwara in June 2019, and questions were later modified to ensure that the subjects would have no difficulty in understanding and answering them. Glucometer, digital sphygmomanometer, measuring tape and weighing scale were used in the study. Following criteria were used.

Hypertension: The hypertension status of the study participants was assessed by using standard criteria formulated by the American Health Association (AHA) $-2017 .^{[13]}$

Diabetes criteria: Blood sugar determination (fasting) was done by glucometer by glucose oxidase

Table 1: Socio-demographic profile of study subjects

\begin{tabular}{|c|c|c|}
\hline \multirow[t]{2}{*}{ Characteristics } & \multicolumn{2}{|c|}{ Total [n=1005] } \\
\hline & Males [n=527] n (\%) & Females $[n=478] n(\%)$ \\
\hline \multicolumn{3}{|l|}{ Age (years) } \\
\hline $10-14$ & $271(51.4)$ & $236(49.4)$ \\
\hline $15-19$ & $256(48.6)$ & $242(50.6)$ \\
\hline \multicolumn{3}{|l|}{ Religion } \\
\hline Hindu & $179(33.9)$ & $154(32.2)$ \\
\hline Muslim & $326(61.9)$ & $306(64)$ \\
\hline Sikh & $17(3.2)$ & $10(2.1)$ \\
\hline Christian & $5(1)$ & $8(1.7)$ \\
\hline \multicolumn{3}{|l|}{ Education } \\
\hline Illiterate & 0 & 0 \\
\hline Primary/ Just literate & $27(5.1)$ & $43(8.9)$ \\
\hline Middle School & $198(37.6)$ & $182(38.2)$ \\
\hline High School & $227(43.1)$ & $219(45.8)$ \\
\hline Intermediate/Diploma & $75(14.2)$ & $34(7.1)$ \\
\hline \multicolumn{3}{|l|}{ Occupation } \\
\hline Student & $403(76.5)$ & $353(73.9)$ \\
\hline School dropout & $22(4.2)$ & $80(16.7)$ \\
\hline Unskilled worker* & $78(14.8)$ & $27(5.7)$ \\
\hline Semi-skilled worker** & $24(4.6)$ & $18(3.8)$ \\
\hline \multicolumn{3}{|l|}{ Marital Status } \\
\hline Married & $12(2.3)$ & $56(11.7)$ \\
\hline Unmarried & $515(97.7)$ & $422(88.3)$ \\
\hline
\end{tabular}

*Unskilled worker: Person who are doing work which requires neither education nor specialized training.

**Semi-skilled worker: person who are doing work which requires some training to know their routine jobs efficiently. 
method as per WHO and were interpreted. In the case of fasting plasma glucose (FPG) $>126 \mathrm{mg} / \mathrm{dl}$, a second determination was performed. ${ }^{[14]}$

Obesity criteria: Body mass index of the person was calculated using height and weight by applying the formula weight (in kgs) divided by square of height (in $\mathrm{m}^{2}$ ).The cutoff criteria are based on the WHO BMIfor-age growth charts. Adolescents with BMI values at or above the $95^{\text {th }}$ percentile of the sex-specific BMI growth charts are classified as obese. ${ }^{[15]}$

Ethical clearance and analysis: Institutional ethical clearance was taken. [No. AIMS/IEC/2019/022]. Statistical analysis was done using SPSS version 21.0.

\section{Results:}

Table 1 shows Majority of the subjects, 403 (76.5\%) males and 353 (73.9\%) females, were students. It was found that $22(4.2 \%)$ males and 80 $(16.7 \%)$ females were school dropouts and not doing anything. Out of 527 males, 24 (4.55\%) and 78 (14.8\%) were semi-skilled and unskilled workers respectively. It was also observed that, 12 (2.3\%) males and 56 (11.7\%) females were married, thereby highlighting the high prevalence of teenage marriage among adolescent girls. [Table 1]

Table 2 highlights that the prevalence of diabetes was $2.9 \%$ in males and $4.4 \%$ in females but the difference was not statistically significant $\left(\chi^{2}=3.66\right.$, $p$ value 0.16 )

Table 3 shows prevalence of smoking, alcoholism, non-vegetarian diet and hypertension was higher among males as compared to females. However, the difference was significant only for smoking $(\chi 2=13.93$, $p$ value $<0.001)$, alcoholism $(\chi 2=36.76, p$ value $<0.001)$ and non-vegetarian $\operatorname{diet}(\chi 2=4.51, p$ value 0.03 ).

Table 2: Prevalence of diabetes among the study subjects

\begin{tabular}{|l|c|c|c|c|}
\hline $\begin{array}{c}\text { Classification of } \\
\text { Diabetes }\end{array}$ & $\begin{array}{c}\text { Males [n= 527] } \\
\mathbf{n}(\mathbf{\%})\end{array}$ & $\begin{array}{c}\text { Females [n=478] } \\
\mathbf{n}(\mathbf{\%})\end{array}$ & $\begin{array}{c}\text { Total [n=1005] } \\
\mathbf{n}(\mathbf{\%})\end{array}$ & $\begin{array}{c}\chi^{2} \text { value, d.f, } \\
\text { p value }\end{array}$ \\
\hline Normal & $485(92)$ & $423(88.5)$ & $908(90.4)$ & \multirow{2}{*}{$3.66,2}$, \\
\hline Prediabetes & $27(5.1)$ & $34(7.1)$ & $61(6.1)$ & 0.16 \\
\hline Diabetes & $15(2.9)$ & $21(4.4)$ & $36(3.6)$ & \\
\hline
\end{tabular}

Table 3 : Prevalence of risk factors of diabetes according to sex among the study subjects

\begin{tabular}{|l|l|l|l|l|}
\hline \multicolumn{1}{|c|}{ Risk Factors } & $\begin{array}{c}\text { Males (N=527) } \\
\mathbf{n ~ ( \% )}\end{array}$ & $\begin{array}{c}\text { Females (N=478) } \\
\mathbf{n}(\mathbf{\%})\end{array}$ & $\begin{array}{c}\text { Total [n=1005] } \\
\mathbf{n}(\mathbf{\%})\end{array}$ & $\begin{array}{c}\boldsymbol{\chi}^{2} \text { value, } \\
\mathbf{p} \text { value }\end{array}$ \\
\hline Family history of diabetes & $66(12.5)$ & $78(16.3)$ & $134(13.3)$ & $2.94,0.08$ \\
\hline Obesity & $33(6.3)$ & $69(14.4)$ & $102(10.2)$ & $18.36,0.001^{* *}$ \\
\hline Sedentary lifestyle\# & $78(14.8)$ & $107(22.4)$ & $185(18.4)$ & $9.6,0.002^{*}$ \\
\hline Smoking & $41(7.8)$ & $12(2.5)$ & $53(5.3)$ & $13.93,0.001^{* *}$ \\
\hline Alcoholism & $57(10.8)$ & $7(1.5)$ & $64(6.4)$ & $36.76,0.001^{* *}$ \\
\hline Non-vegetarian diet & $381(72.3)$ & $316(66.1)$ & $697(69.4)$ & $4.51,0.03^{*}$ \\
\hline Hypertension & $38(7.2)$ & $27(5.7)$ & $65(6.5)$ & $1.01,0.32$ \\
\hline
\end{tabular}

*p value $<0.05{ }^{* *} \mathrm{p}$ value $<0.001$ \# Sedentary: type of lifestyle with little or no physical activity. 
Table 4 : Multivariate Logistic regression analysis of different risk factors for diabetes

\begin{tabular}{|c|c|c|}
\hline Risk factors & Odds ratio ( $95 \% \mathrm{CI})$ & p value \\
\hline \multicolumn{3}{|c|}{ Age group } \\
\hline 10-14 years & Reference & - \\
\hline $15-19$ years & $2.03(1.25-4.03)$ & 0.02 \\
\hline \multicolumn{3}{|c|}{ Socio economic class } \\
\hline Upper/Upper middle & Reference & - \\
\hline Lower middle & $1.09(0.61-1.95)$ & 0.76 \\
\hline Upper lower/ Lower & $1.64(0.85-3.19)$ & 0.13 \\
\hline \multicolumn{3}{|c|}{ BMI } \\
\hline Non obese & Reference & - \\
\hline Obese & $1.86(1.05-3.37)$ & 0.05 \\
\hline \multicolumn{3}{|c|}{ Family history of diabetes } \\
\hline No & Reference & - \\
\hline Yes & $2.16(1.27-3.66)$ & 0.01 \\
\hline \multicolumn{3}{|c|}{ Physical activity } \\
\hline Moderate activity & Reference & - \\
\hline Sedentary lifestyle & $1.90(0.98-3.69)$ & 0.05 \\
\hline \multicolumn{3}{|c|}{ Currently smoking } \\
\hline No & Reference & - \\
\hline Yes & $0.87(0.31-1.67)$ & 0.46 \\
\hline \multicolumn{3}{|c|}{ Diet } \\
\hline Vegetarian & Reference & - \\
\hline Non-vegetarian & $1.93(0.98-2.86)$ & 0.06 \\
\hline \multicolumn{3}{|c|}{ Hypertension } \\
\hline Absent & Reference & - \\
\hline Present & $1.79(1.11-2.45)$ & 0.050 \\
\hline
\end{tabular}

Table 4 highlights that subjects of $15-19$ years age group experienced 2.03 times greater risk of getting diabetes as compared to subjects in the age group of 10-14 years ( $\mathrm{p}$ value 0.02 ). Subjects who were obese experienced 1.86 times greater risk in comparison to those who were not obese ( $p$ value 0.05 ). Subjects with a positive family history of diabetes experienced 2.16 times greater risk of getting diabetes ( $p$ value 0.01). Subjects who led a sedentary lifestyle experienced 1.90 times greater risk of getting diabetes as compared to those engaged in moderate activity ( $p$ value 0.05). Subjects who were hypertensive experienced 1.79 times greater risk as compared to those who were not hypertensive (0.05).

\section{Discussion:}

The prevalence of diabetes in the present study was observed to be $3.6 \%$ among study subjects (2.9\% in males and $4.4 \%$ in females) while the prevalence of prediabetes was observed to be $6.1 \%$ among the study subjects $(5.1 \%$ in males and $7.1 \%$ 
in females). Hence, the combined prevalence of diabetes and prediabetes among the study subjects was observed to be $9.7 \%$. This was observed to be higher than that in the previous studies conducted by Ramachandran et $\mathrm{al}^{[16]}$ among adolescents [12-19 years] in Chennai in 2007 (combined prediabetes and diabetes prevalence of $5.8 \%$ ), by Singh et $\mathrm{al}^{[10]}$ among 10,843 schoolgoing adolescents in Chandigarh in 2007 (4.2\% prevalence of diabetes and $1.6 \%$ prevalence of prediabetes), by Balagopal ${ }^{[17]}$ among adolescent youth [10-17 years] in rural areas of Tamil Nadu in 2008 (combined prevalence of $5.1 \%$ ), and by Reddy ${ }^{[18]}$ among corporate schoolchildren [7-14 years] in Nellore, Andhra Pradesh in 2011 (combined prediabetes and diabetes prevalence of 9.5\%) The present study showed an increasing prevalence of diabetes with increasing age with $2.2 \%$ prevalence of diabetes in the age group of 10-14 years, and 5\% prevalence of diabetes in the age group of 15-19 years ( $p$ value $=0.015$ ). The increasing prevalence of diabetes in the present study could be attributed to urbanization, sedentary lifestyle, physical inactivity and presence of addictions like tobacco use and alcohol consumption.

The present study showed a significantly higher prevalence in subjects with a positive family history of diabetes (11.2\%) as compared to those without positive family history of diabetes $\left(2.4 \%, \chi^{2}=25.94, p\right.$ value $<0.001)$. In a multisite case-control study done in North India by Vikram et $\mathrm{al}^{[19]}$ in 2006, it was found that a significantly higher number of cases had a history of type 2 diabetes in first-degree relatives as compared with controls [82.3\% vs $23.2 \%$, p value $<0.001]$. Anjana $\mathrm{RM}$ et $\mathrm{al}^{[20]}$, in a communitybased study on adolescents [12-19 years] in Chennai, detected that blood sugar levels were significantly higher in the group with two diabetic patients as compared to the groups with one diabetic parent, and no diabetic parents.

The present study showed an increasing prevalence of diabetes with increasing age with $2.2 \%$ prevalence of diabetes in the age group of 10-14 years, and $5 \%$ prevalence of diabetes in the age group of 15-19 years ( $\mathrm{p}$ value $=0.015$ )

The present study showed an increasing prevalence of diabetes with increasing body mass index (BMI), with $2.4 \%$ prevalence of diabetes in non-obese persons compared to $13.7 \%$ prevalence of diabetes in obese persons $\left(\chi^{2}=30.63\right.$, p value $\left.<0.001\right)$. In a multisite case-control study conducted by Vikram et $\mathrm{al}^{[19]}$ among adolescents and young adults in North India in 2006, it was observed that obesity was a risk factor for diabetes [OR=7.9(2.5-25.44)].

The present study showed that the prevalence of diabetes was significantly higher in adolescents who led a sedentary lifestyle (4.6\%) as compared to those doing moderate work $(1.9 \%, \chi 2=5.25$, p value 0.02$)$. (Table 4) These findings are consistent with other studies done either in India or abroad. A multicentric study conducted by Mohan et $\mathrm{al}^{[21]}$ in various parts of India from April 2003-March 2005 as part of the WHO-ICMR Indian NCD risk factor surveillance has found physical inactivity to be a strong risk factor for type 2 diabetes.

\section{Conclusion and Recommendations:}

Overall prevalence of diabetes was found to be $3.6 \%$. Intensive IEC campaigns through multipronged strategies is needed to educate adolescents about diabetes, both in schools from primary level onwards as well as in communities, particularly focusing on - (1) prevention by recognition of important risk factors and lifestyle modifications (2) early diagnosis and treatment by recognition of symptoms.

Healthy lifestyle changes like change in food habits in terms of reduction of salty and fatty food, promotion of balanced diet complemented by regular exercise, weight reduction, etc. should be promoted through all strategies to reduce the prevalence of both diabetes.

\section{Declaration:}

Funding: Nil

Conflict of Interest: Nil 


\section{References:}

1. World Health Organisation. (2001). The Second Decade : Improving Adolescent Health and Development. World health organization. Available at: http://apps.who.int/ iris/handle/10665/64320.

2. United Nations Children's Fund. (2011). The State of the World's Children 2011: Adolescence - An Age of Opportunity. United $\mathrm{Nations}$ Children's Fund. Available at: https://www.unicef.org/reports/state-words-children-2011

3. Chandramouli C. Census of India 2011. Release of Social and Cultural Tables - Age Data Highlights [Internet]. New Delhi; Office of the Registrar-General and Census Commissioner, India [cited on 2014 Apr 21]. Available from: http://www.censusindia.gov.in/2011census/population_ enumeration.aspx.

4. World Health Organisation. The World Health Report 2002: Reducing risks, promoting life. Geneva: WHO; 2002.

5. Botero D, Wolfsdorf JI. Diabetes mellitus in children and adolescents. Arch Med Res. 2005;36(3):281-90.

6. International Diabetes Federation. (2013). IDF Diabetes Atlas. 6th edition, International Diabetes federation, Brussels. Available at: http://www.idf.org/diabetesatlas.

7. Diamond J. Medicine: diabetes in India. Nature. 2011 Jan 27;469(7331):478-9. Doi:10.1038/469478a. PMID:21270882.

8. Bandal SM. A Report on Juvenile Diabetes. Mumbai: Helping Hand Foundation; 2012 . Available at: http://www.helpinghandindia.org/pdf/A-Report-on-JuvenileDiabetes.pdf. [Accessed on September 4,2019.]

9. May AL, Kuklina EV, Yoon PW. Prevalence of cardiovascular disease risk factors among US adolescents, 1999-2008. Pediatrics. 2012;129(6):1035-41.

10. Singh R, Bhansali A, Sialy R, Aggarwal A. Prevalence of metabolic syndrome in adolescents from a north Indian population. Diabetic Medicine. 2007 Feb;24(2):195-9.

11. Mohan V, Sandeep S, Deepa R, Shah B, Varghese C. Epidemiology of type 2 diabetes: Indian scenario. Indian J Med Res. 2007;125:217-30.

12. Reddy AA, Dixit MN, Kumar MR, Jaganmohan P. Evaluation of prevalence of metabolic syndrome in corporate schoolchildren at Nellore district, Andhra Pradesh, India. Global Journal of Biotechnology \& Biochemistry. 2011;6(4):192-6.

13. 2017AHA Guideline for the Prevention, Detection, Evaluation, and Management of High Blood Pressure in Adults: A Report of the American College of Cardiology/American Heart Association Task Force on Clinical Practice Guidelines. Hypertension. Available at: https://www.ahajournals.org/ doi/10.1161/HYP.0000000000000065. (Accessed on 2020 Oct 22)

14. Report of the Expert Committee on the Diagnosis and Classification of Diabetes Mellitus. Diabetes Care 1997; 20:1183-97
15. World Health Organisation. BMI-for-Age Charts [Internet]. Available from: http://www.who.int/growthref/who2007_ bmi_for_age/en/[cited on April 27th, 2020

16. Ramachandran A, Snehalatha C, Yamuna A, Murugesan N, Narayan KM. Insulin resistance and clustering of cardiometabolic risk factors in urban teenagers in southern India. Diabetes Care. 2007;30(7):1828-33.

17. Balagopal P, Kamalamma N, Patel TG, Misra R. A communitybased diabetes prevention and management education program in a rural village in India. Diabetes Care. 2008;31(6):1097-104.

18. Reddy AA, Dixit MN, Kumar MR, Jaganmohan P. Evaluation of prevalence of metabolic syndrome in corporate schoolchildren at Nellore district, Andhra Pradesh, India. Global Journal of Biotechnology \& Biochemistry. 2011;6(4):192-6.

19. Vikram NK, Tandon N, Misra A, Srivastava MC, Pandey RM, Mithal A, et al. Correlates of Type 2 diabetes mellitus in children, adolescents and young adults in north India: a multisite collaborative case-control study. Diabet Med. 2006 Mar;23(3):293-8.

20. Anjana RM, Lakshminarayanan S, Deepa M, Farooq S, Pradeepa R, Mohan V. Parental history of type 2 diabetes mellitus, metabolic syndrome, and cardiometabolic risk factors in Asian Indian adolescents. Metabolism. 2009 Mar;58(3):344-50.

21. Mohan V, Mathur P, Deepa R, Deepa M, Shukla DK, Menon GR, et al. Urban rural differences in prevalence of self-reported diabetes in India--the WHO-ICMR Indian NCD risk factor surveillance. Diabetes Res Clin Pract. 2008 Apr;80(1):159-68. 